\title{
Precautionary Measures Necessary in Liquid Crystal Display (LCD) Television Maintenance by Electronic Technicians
}

\author{
Ifeanyi Benedict Ohanu, Theresa Chinyere Ogbuanya \\ Department of Vocational Teacher Education, University of Nigeria, Nsukka, Nigeria \\ Email: ifeanyi.ohanu@unn.edu.ng
}

Received 29 January 2014; revised 28 February 2014; accepted 7 March 2014

Copyright $@ 2014$ by authors and Scientific Research Publishing Inc.

This work is licensed under the Creative Commons Attribution International License (CC BY).

http://creativecommons.org/licenses/by/4.0/

cc) (i) Open Access

\begin{abstract}
The study was carried out to determine precautionary measures necessary in liquid crystal display (LCD) television maintenance by electronic technician. The population for the study was 3209 consisting of 11 electronic teachers and 3198 electronic technicians. 11 electronic teachers and 155 electronic technicians selected by simple random sampling were used for the study. Questionnaire consisting of 57 items was used to elicit responses from electronic teachers and electronic technicians regarding the two research questions. Data collected were analyzed using mean while t-test for independent sample was used to test the two null hypotheses at 0.05 level of significance. Analysis revealed the important components of LCD television that may occasionally developed faults and important precautionary measures that should be taken in LCD television maintenance. It was concluded that electronic technicians should carry out maintenance of LCD televisions by observing the precautionary measures to be taken in maintenance of LCD televisions.
\end{abstract}

\section{Keywords}

Electronic Technology; Liquid Crystal Display Television; Maintenance; Precautionary Measures; Electronic Technician

\section{Introduction}

Every appliance used by men especially electronic appliances requires maintenance for steady functionality, durability, and even aesthetics. Maintenance is the process of keeping equipment, tools, materials, or system in good working condition. It involves decision making and planning by the personnel. Maintenance of electronic 
appliances can be in various forms such as dusting, lubricating, replacing burnt/damaged components, repairing, testing, using items for the purpose they are designed and following procedure for the operation of each appliance. Different types of maintenance have been mapped out for the maintenance of appliances such as: preventive maintenance, predictive and corrective maintenance. Preventive maintenance is systematic detection and prevention of potential faults before they occur (Bayle, [1]).

According to Operations and Maintenance Best Practices [2], preventive maintenance is actions performed on a time- or machine-run-based schedule that detect, preclude, or mitigate degradation of a component or system with the aim of sustaining or extending its useful life through controlling degradation to an acceptable level. Corrective maintenance can also be referred to as breakdown maintenance. It is the kind of maintenance given to equipment or facility when it cannot function as it is supposed to. It is a response given to an unanticipated problem or emergency [1]. On the other hand, predictive maintenance is the type of maintenance that is carried out on an item/equipment when there is a warning signal of breakdown. It involves arresting the situation promptly before there is any major breakdown that will demand corrective maintenance. According to Operations and Maintenance Best Practices [2], predictive maintenance differs from preventive maintenance by basing maintenance need on the actual condition of the machine rather than on some preset schedule. It is measurement that detects the onset of system degradation (lower functional state), thereby allowing causal stressors to be eliminated or controlled prior to any significant deterioration in the component physical state. Predictive maintenance is usually given on either daily, weekly, bi-weekly or monthly bases. Maintenance is required to be carried out on most electronic gadgets as a result of their complex nature, fragile components used in their construction, miniaturized nature of some components of present-day electronic gadgets, low current/voltage used by electronic gadgets, and so on. Due to their complex and fragile nature, good precautionary measures must be taken in the cause of maintenance of electronic gadgets.

Precautionary measures are carefully taken to avoid damage to equipment. Innovations in the components used in construction of electronic gadgets require serious precautions to be taken in carrying out any maintenance operation or activities on them. This calls technicians who are familiar with the components for effective maintenance of the electronic gadgets. Technicians are trained formally in technical colleges while artisans are trained informally through apprenticeship systems available in the society. Apprenticeship system has been available in Nigeria long before the advent of western system of education. Apprenticeship is the process whereby the apprentice studies the processes involved in a particular job so as to acquire the required skills under the tutelage of his master for a period of six months or over, depending on the agreement that the apprentice reached with his master. It is also a process whereby students try to acquire skills outside school hour which will enable them to work and earn money to take care of their needs while they are still in school. According to Leading Learning Council and Skill [3], apprenticeships are training programmes undertaken in the workplace, giving young people the opportunity to earn money while developing valuable skills and qualifications. It provide the opportunity for learners to "earn and learn" in a wide range of occupations and sectors.

Technicians also enroll in apprenticeship system to learn from their masters by imitation of what their master does. Apprentice-ship system is available in different trades such as blacksmithing, welding, electronic maintenance, electrical installation, and so on. According to Okoro [4], the apprenticeship programme produces semiskilled craftsmen in auto-mechanics, electrical installation, radio and TV repair, carpentry and joinery, cabinet making, building construction and many more areas. Apprentice in electronic maintenance learn skills involved in maintenance of different kinds of electronic gadgets. However, due to innovation in the field of electronics, some of these apprentices limit themselves to learn about the maintenance of few electronic gadgets so as to become efficient in maintenance of such gadgets. Technicians are also trained in technical colleges through formal education. Technical colleges are concerned with production of technicians who are skilled in different fields of human endeavour. The types of technicians produced at technical college level include: electronic/electrical technicians, automobile/metalwork technicians, building/woodwork technicians, and so on. Training of technicians at technical college involves imparting both theoretical and practical knowledge to the students under the guidance of the teacher within the school environment. Students at technical colleges are exposed to different skilled areas, through which one can be trained to become a self-reliant technician. This type of education received at technical college level is known as technical education.

Federal Republic of Nigeria [5] defined technical and vocational education as a comprehensive term referring to those aspects of the educational process involving in addition to general education: the study of technologies and related sciences and the acquisition of practical skills, attitudes, understanding and knowledge relating to 
occupations in various sectors of economic and social life. Technical education is an aspect of education that leads to acquisition of practical and applied skills as well as basic scientific knowledge [4]. At technical college level, technical education is provided to impart technical/occupational skills in the areas of electricity, electronics, metalwork, woodwork, automobile, and so on. This implies that electronic technology is an aspect of technical education.

Electronic technology is the process of applying scientific knowledge in the design, selection of materials, construction, operation and maintenance of electronics [6]. It provides the skills, knowledge and attitudes necessary for effective employment in specific occupation. Electronic technicians produced at technical college level are those that offered courses in electronic technology. They are supposed to be skilled in different areas of electronic technology such as maintenance of electronic gadgets, designing of electronic circuits, as well as construction of some electronic gadgets/appliances.

A technician is a person who is trained formally in a particular trade. Electronic technicians are trained to meet the requirements of man in the ever-changing technological society. One of such prominent changes in the field of electronics is the production of more sophisticated electronic gadgets of which Liquid Crystal Display (LCD) television is one of them. These new and sophisticated gadgets are constructed with different components which are more fragile, complex, costly, and can perform faster than the components used in the construction of earlier developed gadgets. LCD electronic gadgets are new in the society and they are available in different electronic gadgets such as wrist watches, laptop computers, desktop computers, calculators, phones, televisions, and so on.

According to Theraja and Theraja [7], a liquid crystal display is a material (usually, an organic compound) which flows like a liquid at room temperature but whose molecular structure has some properties normally associated with solids (examples of such components are: cholesteryl nonanoate and p-azoxyanisole). Liquid crystal "cell" consists of a thin layer (about $10 \mu \mathrm{m}$ ) of a liquid crystal sandwiched between two glass sheets with transparent electrodes deposited on their inside faces. The LCD materials are used in construction of LCD televisions.

LCD televisions are complex and contain so many fragile components such as the LCD screen, speakers, audio and video components, among others. These components on their own consist of different circuits which are made up of several electronic components like resistors, capacitors, inductors and ICs. The LCD television has the advantage of reduced weight, low power consumption, among others [7]. The advantage of reduced weight of LCD televisions can be attributed to the components that make up LCD televisions which are usually of little weight. The LCD televisions are continuously displacing the use of Cathode Ray Tube (CRT) televisions. The increased level of acceptance of LCD televisions has led to the use of LCD televisions in so many homes, hotels, banks, hospitals, offices, and guest houses. However, these LCD televisions develop fault(s) at one time or the other. This calls for electronic technicians who are skilled in maintenance of LCD televisions to provide remedy to such fault(s).

The kind of remedy given to LCD television fault depends on the type and nature of the problem identified. Some of the ways of solving LCD television faults have been identified by [8]. According to Wistrom [8], if there is no power/image, the power cord should be checked to make sure that it is fully inserted into the outlet. You may want to test the outlet with another appliance to see if there is a problem with the outlet. Turn the power button on, if the picture looks extremely distorted, external devices may be interfering with the signal. Remove any appliances near the television, and see if it works better. Fluorescent lights can also interfere with the image, so you may move the television to a new location. In carrying out the different solutions to the faults of LCD television, a lot of precautionary measures should be taken.

Maintenance of LCD televisions requires a lot of precautionary measures. This is owing to the fact that some sections of the LCD television circuit contain alternating current and high voltage. As such, great care must be taken to avoid electrocution. The following precautionary measures should be taken when working on any LCD television. Don't work alone-in the event of an emergency, another person's presence may be essential. Always keep one hand in your pocket when anywhere around a powered line-connected or high voltage system. Wear rubber bottom shoes or sneakers. Don't wear any jewelry or other articles that could accidentally contact circuitry and conduct current, or get caught in moving parts. Set up your work area away from possible grounds that you may accidentally contact [9]. LCD television set should be unplugged from socket outlets after use. This will help to avoid burning of the fuse or other components during lightening. Goldwasser [9] stated that ideally, electronic equipment should be unplugged (both AC line and phone line) during electrical storms if 
possible. Modern TVs, VCRs, microwave ovens, and even stereo equipment are particularly susceptible to lightning and surge damage because some parts of the circuitry are always alive and therefore have a connection to the AC line.

Sony [10] identified the following precautions to be taken on LCD television: unplug the television and other connected equipment from the wall outlet before you begin cleaning your television; wipe the LCD screen gently with a soft cloth; stubborn stains may be removed with a cloth slightly moistened with a solution of mild soap and warm water; if using a chemically pre-treated cloth, follow the instruction provided on the package; never use strong solvents such as a thinner, alcohol or benzene for cleaning; do not plug in the television into the wall outlet until the moisture from cleaning has evaporated.

No matter the extent of precautions taken, LCD television is a system in use and it is bound to breakdown from time to time. Hence knowledgeable and skilled technicians need to effectively observe precautionary measures and carry out maintenance of LCD television. Such competent electronic technicians will help in ensuring continuous usage of LCD television by the society by offering prompt and effective maintenance services, and they will also be gainfully employed or self-employed. Employment no doubt is one of the most vital instruments needed to speed-off development and curb various societal menaces in Nigeria. Taking good precautions in maintenance of LCD televisions will make the technician involve in maintenance of LCD television to have a good relationship with his customers. This is because good precautionary measures avoid development of other faults to LCD television in the cause of trying to solve existing fault(s). Therefore, this study intends to find out precautionary measures necessary in Liquid Crystal Display (LCD) television maintenance by electronic technicians. Safety precautions are necessary for any meaningful maintenance activity.

\section{Theories}

Safety theory by Weick [11] stated that safety is a dynamic non-event. Non-events, by their nature, tend to be taken for granted, particularly in the face of continuous and compelling productive demands. Safety is invisible in the sense that safe outcomes do not deviate from the expected, and so there is nothing to capture the attention. If people see nothing, they presume that nothing is happening, and that nothing will continue to happen if they continue to act as before. But this is misleading because it takes a number of dynamic inputs to create stable outcomes (James, 1998). This theory is related to this work because it emphasized the need for safety consciousness in maintenance activities. Maintenance of LCD television requires safety in handling the components and parts.

Another theory by James [12] stated that an ideal safety culture is the "engine" that drives the system towards the goal of sustaining the maximum resistance towards its operational hazards, regardless of the leadership's personality or current commercial concerns. This theory is related to this work because it emphasized the need for safety consciousness in maintenance activities. Maintenance of LCD television requires safety in handling the components and parts.

Hudson [13] stated that a safe environment is allowing dangerous activities to take place successfully, which means without harm or damage. What this means is that safety is more than a passive and well-meaning notion, such as "Thou shall do no harm". Instead safety is something that has to be actively managed to allow profit or advantage to be gained. This theory is related to the present study because it emphasized performing dangerous activities successfully. Such dangerous activities which should be performed successfully in maintenance of LCD television include care in handling the screen and the fragile components.

\section{Purpose of the Study}

The major purpose of the study was to find out precautionary measures necessary in liquid crystal display (LCD) television maintenance by electronic technicians. Specifically, the study sought:

1) The important components of LCD television that may occasionally develop faults,

2) The important precautionary measures that should be taken in LCD television maintenance.

\section{Research Questions}

The following research questions guide the study:

1) What are the important components of LCD television that may occasionally develop faults? 
2) What are the important precautionary measures that should be taken in LCD television maintenance?

\section{Hypotheses}

The following hypotheses that guided the study were tested at 0.05 levels of significance:

$\mathrm{Ho}_{1}$ : there is no significant difference between the mean responses of electronic teachers and technicians on the important components of LCD television that may occasionally develop faults.

$\mathrm{Ho}_{2}$ : there is no significant difference between the mean responses of electronic teachers and technicians on the important pre-cautionary measures that should be taken in LCD television maintenance.

\section{Method}

\subsection{Design of the Study}

The design adopted for this study was a descriptive survey research design. Descriptive survey design according to Ezeji [14], is concerned with specifying the properties of educational and other phenomena. The design is appropriate because it sought the representative views of electronic teachers and technicians on the Troubleshooting of Faults in Liquid Crystal Display (LCD) Televisions.

\subsection{Population of the Study and Sampling Procedure}

The population for the study was 3209 persons. This consists of 11 electronic teachers in 10 Government Technical Colleges in Anambra State as well as 3198 electronic technicians in Anambra State. This figure was obtained from Anambra State Post Primary School Management Board [15] and Anambra State Ministry of Commerce and Industry [16]. All the 11 electronic technology teachers in 10 government technical colleges in Anambra State were used for study as well as 155 electronic technicians selected by simple random sampling. According to Gall, Gall, and Borg [17], simple random sampling is the selection from a population through the process that provides every sample of a given size an equal probability of being selected. The teachers and the electronic technicians have similar culture.

\subsection{Procedure}

The questionnaire was the instrument used for eliciting responses from the respondents. The questionnaire was divided into three sections namely section A and section B, which consisted of 57 structured items. Section sought information on the important components of LCD television that may occasionally develop faults. Section B sought information on the important precautionary measures that should be taken in LCD television maintenance. The questionnaire utilized a 4-point scale of the questionnaire items was rated as follows: Very Important (VI), Important (I), Moderately Important (MI), and Not Important (UI) for research the two research questions. Three experts, two from department of Vocational Teacher Education, University of Nigeria, Nsukka and one technician were requested to carry out face validation of the instrument. Their comments, suggestions and advice were used to modify some of the items. The reliability of the instrument was established by trial testing using electronic teachers and technicians in Enugu State. Cronbach Alpha was used to determine the internal consistency of the items in the instrument. A reliability coefficient of 0.89 was obtained.

The researcher administered and collects the instrument with the help of six research assistants. The research assistants were requested to administer the instrument to the respondents and collect them immediately after completion by the respondents. The respondents were required to provide information that represent their opinion out of the available response alternative in the questionnaire. The instrument was collected immediately after its administration, the same day. It took two weeks to administer and collect the instrument and $95 \%$ of the administered instrument was returned. Data collected for this study was analyzed using mean. t-test for independent samples was used to test the hypothesis at 0.05 level of significance. The response to the items was interpreted using table of real limit of numbers as follows: Very Important $(\mathrm{VI})=3.50-4.00$; Important $(\mathrm{I})=2.50$ - 3.49; Moderately Important $(\mathrm{MI})=1.50-2.49$; Not Important $(\mathrm{NI})=0.50-1.49$. Base on the above limits, any item that has a mean score of 3.50 - 4.00 was regarded as Very Important, 2.50 - 3.49 was regarded as Important, 1.50 - 2.49 was regarded as Moderately Important, 0.50 - 1.49 was regarded as Not Important. 


\section{Results}

\subsection{Table 1}

Data presented in Table 1 show that all the items had their mean value ranging from 3.46 to 3.54 which falls within the response categories of Important and Very Important. This indicates that the items 1, 2, 19, 21, 24, 25, 27, 28, and 29 are important components of LCD television with their mean scores ranging from 3.46 to 3.49 . While items 3 to 18, 20, 22, 23, 26, and 30 to 32 are Very Important components of LCD television with mean scores ranging from 3.50 to 3.56. The standard deviation for the items ranges from 0.54 to 0.64 . This implies that the Electronic technology teachers and the Electronic technicians are homogenous in their responses on the important components of LCD television.

The result also shows that there is a significant difference in the mean responses of Electronic Teachers and Electronic Technicians on items 1, 2, 3, 7, 10, 11, 17 to 23, 29, and 31. Since their significance level ranges from 0.004 to 0.047 . Therefore, the null hypothesis of no significance difference at 0.05 level of Significance was rejected for those items.

Table 1. Mean ratings, standard deviation and t-test analysis of responses of electronic technology teachers and technicians on the important components of LCD television that may occasionally develop faults.

\begin{tabular}{|c|c|c|c|c|c|c|}
\hline $\mathbf{s} / \mathbf{n}$ & $\begin{array}{l}\text { Important components of LCD television } \\
\text { that may occasionally develop faults }\end{array}$ & $\overline{\boldsymbol{X}}$ & S.D & t-test & Sig. (2-tailed) & Decision \\
\hline 1 & Capacitors & 3.46 & 0.61 & 2.952 & 0.004 & $S$ \\
\hline 2 & Inductors & 3.49 & 0.62 & 2.486 & 0.014 & S \\
\hline 3 & Tuner & 3.51 & 0.62 & 2.002 & 0.047 & $\mathrm{~S}$ \\
\hline 4 & Integrated circuit & 3.53 & 0.59 & 1.618 & 0.108 & NS \\
\hline 5 & Video and audio demodulators & 3.51 & 0.63 & 1.407 & 0.161 & NS \\
\hline 6 & Transistors & 3.54 & 0.60 & 1.080 & 0.282 & NS \\
\hline 7 & LCD screen & 3.51 & 0.63 & 2.576 & 0.011 & $\mathrm{~S}$ \\
\hline 8 & Speakers & 3.50 & 0.64 & 1.875 & 0.063 & NS \\
\hline 9 & Deflection yoke & 3.51 & 0.64 & 1.937 & 0.055 & NS \\
\hline 10 & Power button & 3.52 & 0.62 & 2.069 & 0.040 & S \\
\hline 11 & Resistors & 3.51 & 0.62 & 2.621 & 0.010 & S \\
\hline 12 & Connectors & 3.54 & 0.57 & 1.754 & 0.081 & NS \\
\hline 13 & Diodes & 3.51 & 0.59 & 1.516 & 0.132 & NS \\
\hline 14 & Ambient sensors & 3.54 & 0.56 & 1.166 & 0.246 & NS \\
\hline 15 & IR receivers & 3.50 & 0.59 & 1.448 & 0.150 & NS \\
\hline 16 & Carbon & 3.51 & 0.59 & 1.482 & 0.140 & NS \\
\hline 17 & Sockets & 3.51 & 0.63 & 2.542 & 0.012 & $\mathrm{~S}$ \\
\hline 18 & Fuse & 3.51 & 0.61 & 2.072 & 0.040 & S \\
\hline 19 & Coils & 3.49 & 0.62 & 2.519 & 0.013 & S \\
\hline 20 & Photocoupler & 3.50 & 0.59 & 2.041 & 0.043 & S \\
\hline 21 & Varistor & 3.49 & 0.61 & 2.565 & 0.011 & S \\
\hline 22 & Filter & 3.50 & 0.59 & 2.041 & 0.043 & S \\
\hline 23 & Deflection coils & 3.51 & 0.61 & 2.633 & 0.009 & $\mathrm{~S}$ \\
\hline 24 & Ferrite bead & 3.47 & 0.63 & 1.249 & 0.213 & NS \\
\hline 25 & Vibrator crystal & 3.47 & 0.62 & 1.270 & 0.206 & NS \\
\hline 26 & Ultrafast rectifiers & 3.50 & 0.62 & 0.604 & 0.547 & NS \\
\hline 27 & Supply cord & 3.49 & 0.58 & 1.442 & 0.151 & NS \\
\hline 28 & Light emitting diodes & 3.49 & 0.61 & 0.785 & 0.433 & NS \\
\hline 29 & $\mathrm{X} / \mathrm{Y}$ capacitors & 3.49 & 0.59 & 2.007 & 0.046 & $\mathrm{~S}$ \\
\hline 30 & Secondary protection fuses & 3.50 & 0.59 & 0.865 & 0.388 & NS \\
\hline 31 & Hook & 3.50 & 0.62 & 2.553 & 0.012 & $\mathrm{~S}$ \\
\hline 32 & Remote controller & 3.52 & 0.60 & 1.522 & 0.130 & NS \\
\hline
\end{tabular}

Key: NS = Not Significant, S = Significant, df = Degree of freedom (156), t-cal = Calculated value of t-test using SPSS, S.D = Standard Deviation, $\overline{\boldsymbol{X}}_{1}=$ Mean for electronic technicians, $\overline{\boldsymbol{X}}_{2}=$ Mean for electronic teachers, $\mathrm{n}_{1}=$ Number of electronic technicians, $\mathrm{n}_{2}=$ Number of electronic teachers, level of significance $=0.05$. 
The result also revealed that there was no significance difference in the mean responses of Electronic Teachers and Electronic Technicians on items 4, 5, 6, 8, 9, 12 to 16, 24 to 28, 30, and 32. Since their significance ranges from 0.055 to 0.547 which are more than 0.05 level of significance. Therefore, the hypothesis of no significance difference was not rejected at 0.05 level of significance for those items.

\subsection{Table 2}

Data presented In Table 2 shows that all the items had their mean ranging from 3.28 to 3.45 which falls within

Table 2. Mean, standard deviation and t-test analysis of responses of electronic technology teachers and technicians on the important precautionary measures that should be taken in LCD television maintenance.

\begin{tabular}{|c|c|c|c|c|c|c|}
\hline $\mathbf{s} / \mathbf{n}$ & $\begin{array}{l}\text { Important precautionary measures that should be taken in LCD } \\
\text { television maintenance. }\end{array}$ & $\overline{\boldsymbol{X}}$ & S.D & t-cal & $\begin{array}{l}\text { Sig. } \\
\text { (2-tailed) }\end{array}$ & Decision \\
\hline 34 & $\begin{array}{l}\text { Unplug the TV and other connected equipment from the wall outlet before you begin } \\
\text { cleaning your TV. }\end{array}$ & 3.42 & 0.70 & 1.419 & 0.158 & NS \\
\hline 35 & Wipe the LCD screen gently with a soft cloth. & 3.42 & 0.66 & 1.440 & 0.152 & NS \\
\hline 36 & $\begin{array}{l}\text { Ensure TV securely mounted on a stable surface before you begin loosen the parts to } \\
\text { present it from toppling over. }\end{array}$ & 3.45 & 0.66 & 1.583 & 0.116 & NS \\
\hline 37 & $\begin{array}{l}\text { Stubborn stains may be removed with a cloth slightly moistened with a solution of } \\
\text { mild soap and warm water. }\end{array}$ & 3.44 & 0.65 & 2.118 & 0.036 & $\mathrm{~S}$ \\
\hline 38 & $\begin{array}{l}\text { Do not plug in the TV into the wall outlet until the moisture from cleaning has } \\
\text { evaporated. }\end{array}$ & 3.45 & 0.66 & 2.116 & 0.036 & $\mathrm{~S}$ \\
\hline 39 & $\begin{array}{l}\text { If using a chemically pre-treated cloth in cleaning the TV, follow the instruction } \\
\text { provided on the package. }\end{array}$ & 3.41 & 0.66 & 0.857 & 0.393 & NS \\
\hline 40 & $\begin{array}{l}\text { Strong solvents such as a thinner, alcohol or benzene should not be used for cleaning } \\
\text { LCD TV. }\end{array}$ & 3.42 & 0.63 & 0.987 & 0.325 & NS \\
\hline 41 & LCD TV screen should not be exposed to direct illumination or sunlight. & 3.42 & 0.65 & 0.957 & 0.340 & NS \\
\hline 42 & Do not install LCD television in a room with reflective wall and floor materials. & 3.41 & 0.64 & 0.884 & 0.378 & NS \\
\hline 43 & LCD television should not be moved from a cold area to a warm area. & 3.41 & 0.64 & 0.376 & 0.708 & NS \\
\hline 44 & LCD television should not be exposed to rain or excessive moisture. & 3.41 & 0.63 & 0.898 & 0.371 & NS \\
\hline 45 & $\begin{array}{l}\text { When turning off the TV by detaching the power cable or DC power cord, wait for } 6 \\
\text { seconds before attach the power cable or DC power cord for normal operation. }\end{array}$ & 3.41 & 0.64 & 0.376 & 0.708 & NS \\
\hline 46 & Ventilation holes on the television cabinet should not be blocked. & 3.37 & 0.64 & 0.725 & 0.470 & NS \\
\hline 47 & $\begin{array}{l}\text { Don't work alone so that in the event of an emergency another person's presence } \\
\text { may be essential. }\end{array}$ & 3.39 & 0.63 & 0.290 & 0.836 & NS \\
\hline 48 & $\begin{array}{l}\text { Always keep one hand in your pocket when anywhere around a powered } \\
\text { line-connected or high voltage system. }\end{array}$ & 3.37 & 0.62 & -0.383 & 0.702 & NS \\
\hline 49 & Wear rubber bottom shoes or sneakers when working on LCD television. & 3.41 & 0.63 & -0.193 & 0.847 & NS \\
\hline 50 & $\begin{array}{l}\text { Work area should be set-up away from possible grounds that you may accidentally } \\
\text { contact. }\end{array}$ & 3.35 & 0.64 & 0.102 & 0.919 & NS \\
\hline 51 & $\begin{array}{l}\text { Don't wear any jewelry or other articles that could accidentally contact circuitry and } \\
\text { conduct current, or get caught in moving parts. }\end{array}$ & 3.35 & 0.63 & 0.103 & 0.918 & NS \\
\hline 52 & Use an isolation transformer if there is any chance of contacting line connected circuits. & 3.34 & 0.64 & -0.497 & 0.620 & NS \\
\hline 53 & $\begin{array}{l}\text { If you must probe live, put electrical tape over all but the last } 1 / 16 " \text { of the test probes } \\
\text { to avoid the possibility of an accidental short which could cause damage to various } \\
\text { components. }\end{array}$ & 3.32 & 0.64 & 0.483 & 0.630 & NS \\
\hline 54 & Perform as many tests as possible with power off and the equipment unplugged. & 3.31 & 0.66 & 0.412 & 0.681 & NS \\
\hline 55 & Avoid working when you are really tired. & 3.29 & 0.66 & 0.321 & 0.749 & NS \\
\hline 56 & $\begin{array}{l}\text { Unplug the TV set from socket outlet after use to avoid burning of fuse or other } \\
\text { electronic components as a result of lightening. }\end{array}$ & 3.28 & 0.67 & 0.260 & 0.795 & NS \\
\hline 57 & $\begin{array}{l}\text { If the television clicks with power-on but no other action, check other fuses in the } \\
\text { circuit and replace them accordingly. }\end{array}$ & 3.39 & 0.62 & -4.312 & 0.001 & $\mathrm{~S}$ \\
\hline
\end{tabular}

Key: NS = Not Significant, S = Significant, $\mathrm{df}=$ Degree of freedom, t-cal = Calculated value of t-test using SPSS, S.D = Standard Deviation, $\overline{\boldsymbol{X}}_{1}=$ Mean for electronic technicians, $\overline{\boldsymbol{X}}_{2}=$ Mean for electronic teachers, $\mathrm{n}_{1}=$ Number of Electronic technicians, $\mathrm{n}_{2}=$ Number of electronic teachers, level of significance $=0.05$. 
the response categories of Important. This indicates that all the items are the important precautionary measures that should be taken in LCD television maintenance. The standard deviation for the items ranges from 0.62 to 0.67. This implies that the Electronic Teachers and Electronic Technicians are homogenous in their responses on the important precautionary measures that should be taken in LCD television maintenance. The result also shows that there is a significant difference in the mean responses of Electronic Teachers and Electronic Technicians on items 37,38 , and 57 . Since their significance level are $0.036,0.036$, and 0.001 respectively which are less than 0.05 level of significance. Therefore, the null hypothesis of no significance difference at 0.05 level of significance was rejected for those items.

The result also revealed that there was no significance difference in the mean responses of Electronic Teachers and Electronic Technicians on items 33 to 36, and 39 to 56. Since their significance level ranges from 0.116 to 0.919 which are more than 0.05 level of significance. Therefore the null hypothesis of no significance difference was not rejected at 0.05 level of significance for those items.

\section{Discussion}

The result of this study revealed that 32 items constitute the important components of LCD televisions as indicated by the responses of the respondents. The items are: capacitors, inductors, tuner, integrated circuit, video and audio demodulators, transistors, LCD screen, speakers, deflection yoke, power button, resistors, connectors, diodes, ambient sensors, IR receiver, carbon, sockets, fuse, coils, photocoupler, varistor, filter, deflection coils, ferrite bead, vibrator crystal, ultrafast rectifiers, supply cord, light emitting diodes, X/Y capacitors, secondary protection fuses, hook, and remote controller. This is in line with Au Optronics Corporation [18], [9] and Lewis [19]. Au Optronics Corporation [18] identified the main components of LCD television as power board, tuner, IR board, remote controller, LCD panel, back cover, chassis, stand, and keypad board. Some of the components of LCD television identified by Goldwasser [9] include: horizontal deflection, vertical deflection, LCD screen, chroma, demodulator, sync separators, among others.

The result of the analysis of the hypothesis revealed that there was no significant difference in the responses of electronic technology teachers and electronic technicians on 17 important components of LCD televisions that occasionally develop faults. However, significant difference existed in the respondents responses on 15 items as can be seen from Table 1. The hypothesis of no significant difference was upheld for 17 items, but was rejected for 15 items (see Table 1). Majority of the respondents agreed that the identified components are the important components of LCD televisions that occasionally develop faults. The above findings supports [18], who identified the main components of LCD television as power board, tuner, IR board, remote controller, LCD panel, back cover, chassis, stand, and keypad board. The findings are also consistent with Goldwasser [9] who identified some components of LCD television to include: horizontal deflection, vertical deflection, LCD screens, chroma, demodulator, sync separators, and so on.

The result of the study shows that the following 25 items are the important precautionary measures that should be taken in maintenance of LCD televisions: the items are as follows: wear cotton gloves while troubleshooting, to avoid electrical shock, unplug the TV and other connected equipment from the wall outlet before you begin cleaning your TV, wipe the LCD screen gently with a soft cloth, ensure TV is securely mounted on a stable surface before you begin loosen the parts to present it from toppling over, stubborn stains may be removed with a cloth slightly moistened with a solution of mild soap and warm water, do not plug in the TV into the wall outlet until the moisture from cleaning has evaporated, if using a chemically pre-treated cloth in cleaning the TV follow the instruction provided on the package, strong solvents such as a thinner, alcohol or benzene should not be used for cleaning LCD TV, LCD TV screen should not be exposed to direct illumination or sunlight, do not install LCD television in a room with reflective wall and floor materials, LCD television should not be moved from a cold area to a warm area, LCD television should not be exposed to rain or excessive moisture, when turning off the TV by detaching the power cable or DC power cord wait for 6 seconds before attach the power cable or DC power cord for normal operation, ventilation holes on the television cabinet should not be blocked, don't work alone so that in the event of an emergency another person's presence may be essential, always keep one hand in your pocket when anywhere around a powered line-connected or high voltage system, wear rubber bottom shoes or sneakers when working on LCD television, work area should be set-up away from possible grounds that you may accidentally contact, don't wear any jewellery or other articles that could accidentally contact circuitry and conduct current, or get caught in moving parts, use an isolation transformer if there 
is any chance of contacting line connected circuits, if you must probe live, put electrical tape over all but the last $1 / 16$ " of the test probes to avoid the possibility of an accidental short which could cause damage to various components, perform as many tests as possible with power off and the equipment un-plugged, avoid working when you are really tired, unplug the TV set from socket outlet after use to avoid burning of fuse or other electronic components as a result of lightening, and if the television clicks with power-on but no other action, check other fuses in the circuit and replace them accordingly. This result is in consonance with [9]. Goldwasser [9], identified some of the precautionary measures as wearing rubber shoes or sneakers, not wearing jewellery, among others. This is an indication that accident may occur especially electrocution when working in any current device or appliance without wearing protective shoes.

The result of the analysis of the hypothesis revealed that there was no significant difference in the responses of electronic technology teachers and electronic technicians on 29 important precautionary measures that should be taken in maintenance of LCD television faults. However, significant difference existed in the respondents responses on only three items as can be seen from Table 2. The hypothesis of no significant difference was upheld for 29 items, but was rejected for 3 items (see Table 2). Majority of the electronic technology teachers and electronic technicians rated the important precautionary measures that should be taken in maintenance of LCD television faults the same way. The result confirms the findings of Goldwasser [9], who identified some of the precautionary measures as wearing rubber shoes or sneakers as well as not wearing jewellery.

\section{Conclusion}

Based on the findings of the study, the following conclusions were made: LCD televisions are new in the society and their maintenance should be taught as a separate topic in electronic technology. Electronic technicians should carry out maintenance of LCD televisions by observing the precautionary measures to be taken in maintenance of LCD televisions. This will avoid damaging other components or sections that are working properly.

\section{References}

[1] Bayle, T. (2007) Preventive Maintenance Strategy for Data Centres. American Power Conversion, America.

[2] Operations \& Maintenance Best Practices (2011) A Guide to Achieving Operational Efficiency Chapter 5, Types of Maintenance Programmes, Release 3.0.

[3] Leading Learning Council and Skill, Apprenticeships: 2005 (2011) www.apprenticeships.org.uk

[4] Okoro, O.M. (1999) Principles and Methods in Vocational and Technical Education. University Trust Publishers, Nsukka.

[5] Federal Republic of Nigeria (2004) National Policy on Education (Revised Edition). Nigeria Education Research and Development Council (NERDC) Press, Lagos.

[6] Theraja, B.L. (2007) Basic Electronic Solid States. S. Chand and Company Ltd., India.

[7] Theraja, B.L. and Theraja, A.K. (2007) A Text Book of Electrical Technology. S. Chand and Company Ltd., India.

[8] Wistrom, E. (2011) Common Vizio LCD TV Problems \& Solutions. http://www.vizio.com/contacts/

[9] Goldwasser, S.M. (2011) Notes on the Troubleshooting and Repair of Television Sets, Version 3.30.

[10] Sony, LCD Digital Colour TV (2010) http://www.sony.net/

[11] Weick, K.E. (1991) Organizational Culture as a Source of High Reliability. In: James, R., Achieving a Safe Culture: Theory and Practice. http://www.shef.ac.uk/ mcn/6810/reading/reason-1998-safety-culture.pdf

[12] James, R. (1998) Achieving a Safe Culture: Theory and Practice. http://www.shef.ac.uk/ mcn/6810/reading/reason-1998-safety-culture.pdf.

[13] Hudson, P. (1999) Safety Culture-Theory and Practice. RTO HFM Workshop on "The Human Factor in System Reliability - Is Human Performance Predictable?”, Siena, 1-2 December 1999, Published in RTO MP-032.

[14] Ezeji, S.C.O.A. (2004) Basic Principles of Research in Education. Cheston Agency Ltd., Enugu.

[15] Anambra State Post Primary School Management Board (2011) Population of Electrical/Electronic Technology Teachers. Statistics Department.

[16] Anambra State Ministry of Commerce and Industry (2012) Population of Radio and Television Repairers in Anambra State. Anambra State Radio and Television Repairers Association, Anambra.

[17] Gall, M.D., Gall, J.P. and Borg, W.R. (2007) Educational Research an Introduction. 8th Edition, Pearson. 
[18] AU Optronics Corporation (2010) Product-Category Rules (PCR) for Preparing an Environmental Product Declaration (EPD) for TFT-LCD Televisions. AU Optronics Corporation, Taiwan.

[19] Lewis, K. (2004) Sony LCD Television Service Manual. Sony Corporation Sony UK Service Promotions Department, UK. 